Article

\title{
A Novel Fault Diagnosis Method for High-Temperature Superconducting Field Coil of Superconducting Rotating Machine
}

\author{
Seunghyun Song ${ }^{1}$, Tae Kuk Ko ${ }^{2}$, Yojong Choi ${ }^{2}$ and SangGap Lee ${ }^{1, *}$ \\ 1 Korea Basic Science Institute, Cheongju 28119, Korea; chocobinu86@kbsi.re.kr \\ 2 School of Electrical and Electronic Engineering, Yonsei University, Seoul 03722, Korea; \\ tkko@yonsei.ac.kr (T.K.K.); cyj7287@yonsei.ac.kr (Y.C.) \\ * Correspondence: sgl757@kbsi.re.kr
}

Received: 25 October 2019; Accepted: 23 December 2019; Published: 27 December 2019

check for updates

\begin{abstract}
In this paper, a new method is presented for sensitive quench detection in high-temperature superconductor (HTS) rotating machinery. The normal zone propagation velocity of an HTS is about 1000 times slower than that of a low-temperature superconductor. Therefore, the propagation of normal zone resistance, which occurs when the HTS transits from the superconducting state to the normal state, is also slower. Thus, it is difficult to detect the abnormal signals by voltage measurement using voltage taps. Moreover, the monitoring signal includes noise generated by interaction between the HTS rotating machinery and the industrial environment. Therefore, when quenching occurs in the HTS rotating machinery, a thermal runaway occurs in the hot spot. Furthermore, the magnetic energy stored in the HTS coil can damage the machinery. For these reasons, a new method is proposed for sensitive quench detection that reduces the noise generated from the power supply and from the HTS rotating machinery, using both an RLC resonance circuit and fast Fourier transform analysis.
\end{abstract}

Keywords: high-temperature superconductor; noise; resonance circuit; rotating machinery; quench detection

\section{Introduction}

Many research groups have studied quench detection methods for low-temperature superconductor (LTS) systems using voltage taps to measure abnormal voltage signals. However, quench detection in high-temperature superconductor (HTS) coils is more difficult to detect than that of LTS coils. The normal zone propagation velocity (NZPV) of an HTS is about 1000 times slower than for an LTS coil. Therefore, thermal runaway can occur in a hot spot and damage the HTS coil due to stored magnetic energy before the resistance generated in the normal zone can be measured. For these reasons, various quench detection methods that do not use a traditional voltage tap have been studied [1-5]. Ravaioli et al. proposed a quench detection method based on the change in stray capacitance between magnet elements when quenching occurred [1]. This method comprehensively determines whether or not quenching occurs due to factors such as cryogenic fluid boil-off, variation of the dielectric properties of the insulation material, and thermal expansion, which changes the local distance between a coil and metal parts. However, because there is drift for a long time when the quench signal is measured that corresponds to the change in capacitance, the reliability of the quenching detection is decreased. In addition, the capacitance monitoring system is temporarily interrupted by circuit transients, which is a drawback in quench detection. Other quench detection methods that do not rely on voltage taps have also been studied, including such as acoustic emission [2,3], telemetry [4], and strain gauges $[5,6]$. A universal quench detection technique was proposed by Nanato et al. with active 
power detection using a central voltage tap $[7,8]$. With this method, a central voltage tap measures the voltage imbalance with a reduced noise signal achieved using a low-pass filter (LPF). However, this method has the limitation that it can cause a short circuit to a large magnet when high voltage is applied. More studies to improve the reliability of quench detection by reducing the electromagnetic noise continued to be conducted by Nanato and Nakamura [9]. This technique is related to noise reduction through inductive voltage cancellation of the HTS coil, and can increase quench detection reliability through the cancel coil and LPF. However, in order to cancel the inductive voltage, an air-core solenoid coil must be installed. Hasegawa et al. proposed a new method using LTS wire as a quench detector [10]. That is, when an LTS is installed in the stabilization layer using epoxy, it is attached to the REBCO coil again, and when a normal zone is generated in the REBCO coil, current is passed through the stabilizer layer, which causes quenching in the LTS wire. Finally, the abnormal signal of the REBCO coil is indirectly detected by the LTS wire. However, to utilize this method, the REBCO coil must be impregnated with the epoxy surrounding the LTS, which may limit increase in the coil volume. In addition, LTS quench detection by heating the epoxy should be preceded by quench detection for the REBCO coil. However, extension of the quench detection time causes fatal damage to an HTS coil because of its slow NZPV. Furthermore, quench detection in HTS rotating machinery is even more difficult. This is because the monitoring signal of the HTS rotating machinery contains noise due to interaction with the industrial environment. For these reasons, in this paper, it is proposed that a new method for sensitive quench detection in HTS rotating machinery using an RLC resonant circuit is utilized. The RLC resonant circuit acts as a band-pass filter and reduces the influence of noise in the detection of quenching [11,12]. The feasibility of the proposed quench detection method is confirmed by simulation results and equivalent circuit analysis. The simulation results are also verified through experiments.

\section{Analysis of a New Active Quench Detection Method for High-Temperature Superconducting Magnets}

\subsection{Concept of the Proposed Method}

The quench detection method proposed in this paper has the following advantages. First, due to the transfer function characteristics of the resonance filter, the noise amplitude of the measured signal can be reduced. Second, because the proposed method detects abnormal signals in the frequency domain, it can compensate for the disadvantage of slow NZPV in the HTS. Third, the quench detection time can be shortened by adjusting the window size of the moving average when performing the FFT analysis. Figure 1 shows a flow chart of the novel fault diagnosis method for a HTS field coil of a superconducting rotating machine.

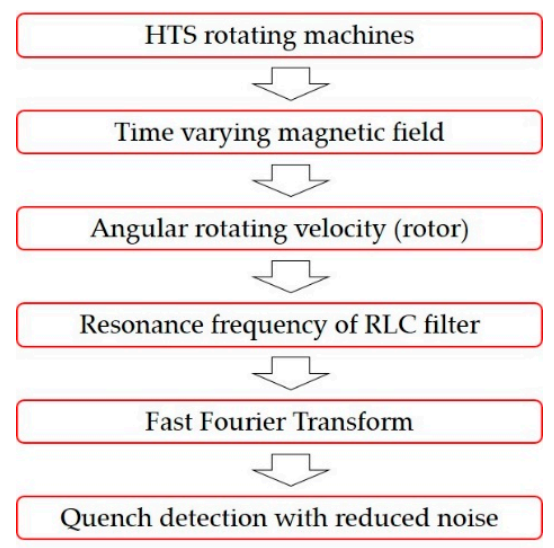

Figure 1. Flow chart of novel fault diagnosis method for superconducting rotating machine. 
Figure 2 shows an equivalent circuit of the proposed quench detection method. The circuit consists of a superconducting coil part, a parallel resonant circuit part, a voltage measurement part, and a quench detection part. In the equivalent circuit, the superconducting stator coil is described by $L_{i n s}$ and $R_{\theta}$, which indicate the self-inductance and azimuthal resistance, respectively, of the superconducting stator coil. The self-inductance of a superconducting rotor coil is $L_{B}$, which is electromagnetically linked to a superconducting stator coil. The term $V_{a c}$ represents an alternating voltage source used to transport the alternating field to the superconducting stator coil $[13,14]$. Here, $R_{\text {div }}$ is a resistor for adjusting the magnitude of the voltage induced in the superconducting stator coil and $I_{d c}$ is a current source for applying a direct current to the superconducting stator coil. The term $R_{R}$ is the radial resistance of the un-insulated coil [15]. Here, $C_{v a r}$ is a variable capacitor for tuning the resonance frequency and $R_{\text {ext }}$ is a resistor for measuring the voltage of the circuit. The terms $L_{i n s}, C_{v a r}$, and $R_{e x t}$ are the components of a parallel resonant circuit with a stator coil in superconducting state. The resonance frequency of the circuit is tuned to be equal to the rotation frequency of the rotor coil.

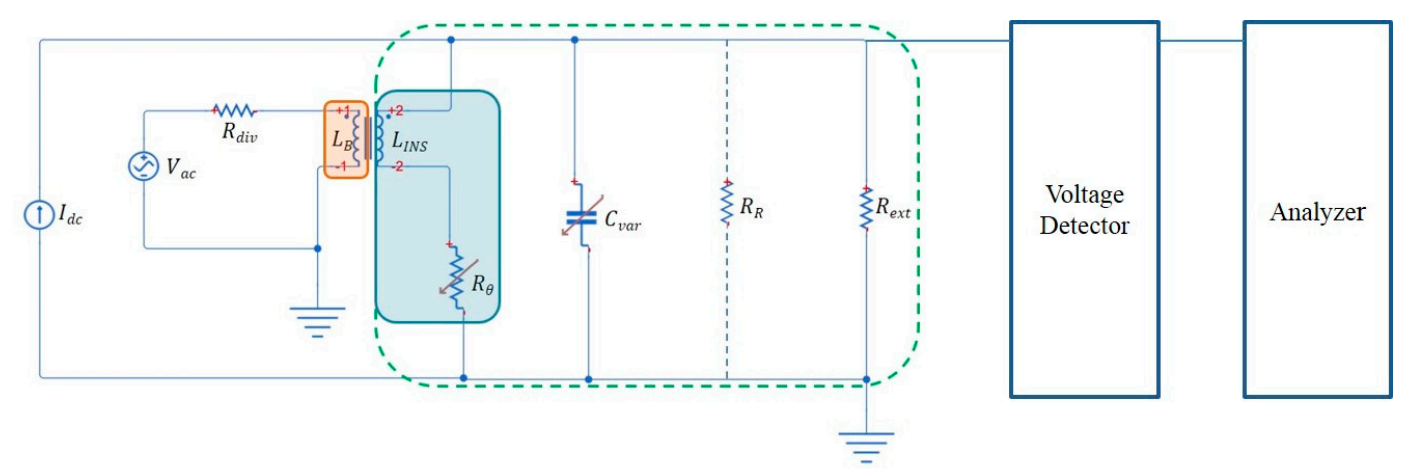

Figure 2. Equivalent circuit of the proposed quench detection method.

Figure 3 shows an equivalent circuit to explain the method of detecting the quench through $R_{\text {ext }}$ when $R_{\theta}$ is generated in the stator coil. The currents flowing to the stator coil and $R_{e x t}$ are called $i_{1}$ and $I_{2}$, respectively. The sum of the two currents is the same as $I_{T}$, and $I_{1}$ is equal to $I_{T}$ because the impedance of the stator coil is zero when the stator coil is in superconducting state. However, as the stator coil transits from superconducting to normal state, $R_{\theta}$ is generated, so that $I_{2}$ flows toward $R_{e x t}$.

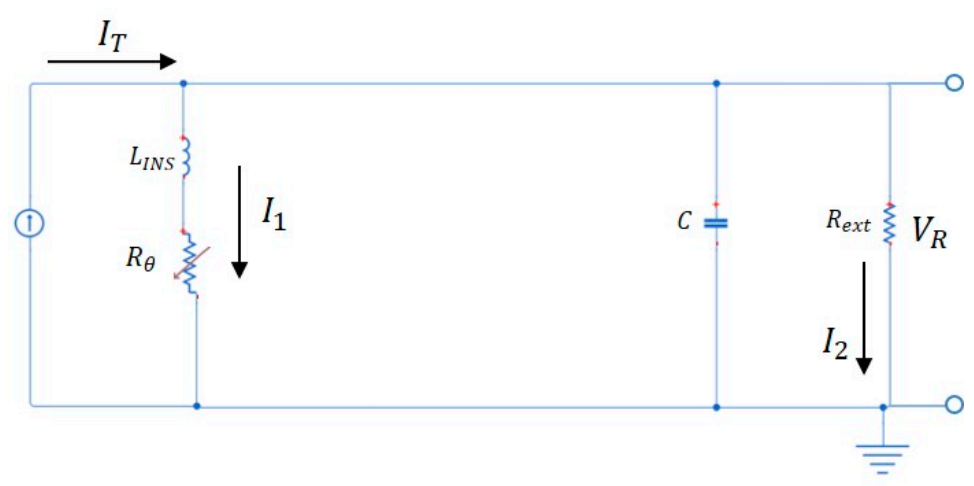

Figure 3. Equivalent circuit to explain the quench detection method.

Therefore, the voltage across $R_{\text {ext }}$ is measured, then the quenching can be detected by performing FFT analysis because the amplitude of the transfer function is proportional to that of the output voltage.

\subsection{Simulation Results}

Figure 4 shows the equivalent circuit for the simulation of the proposed quench detection method. 


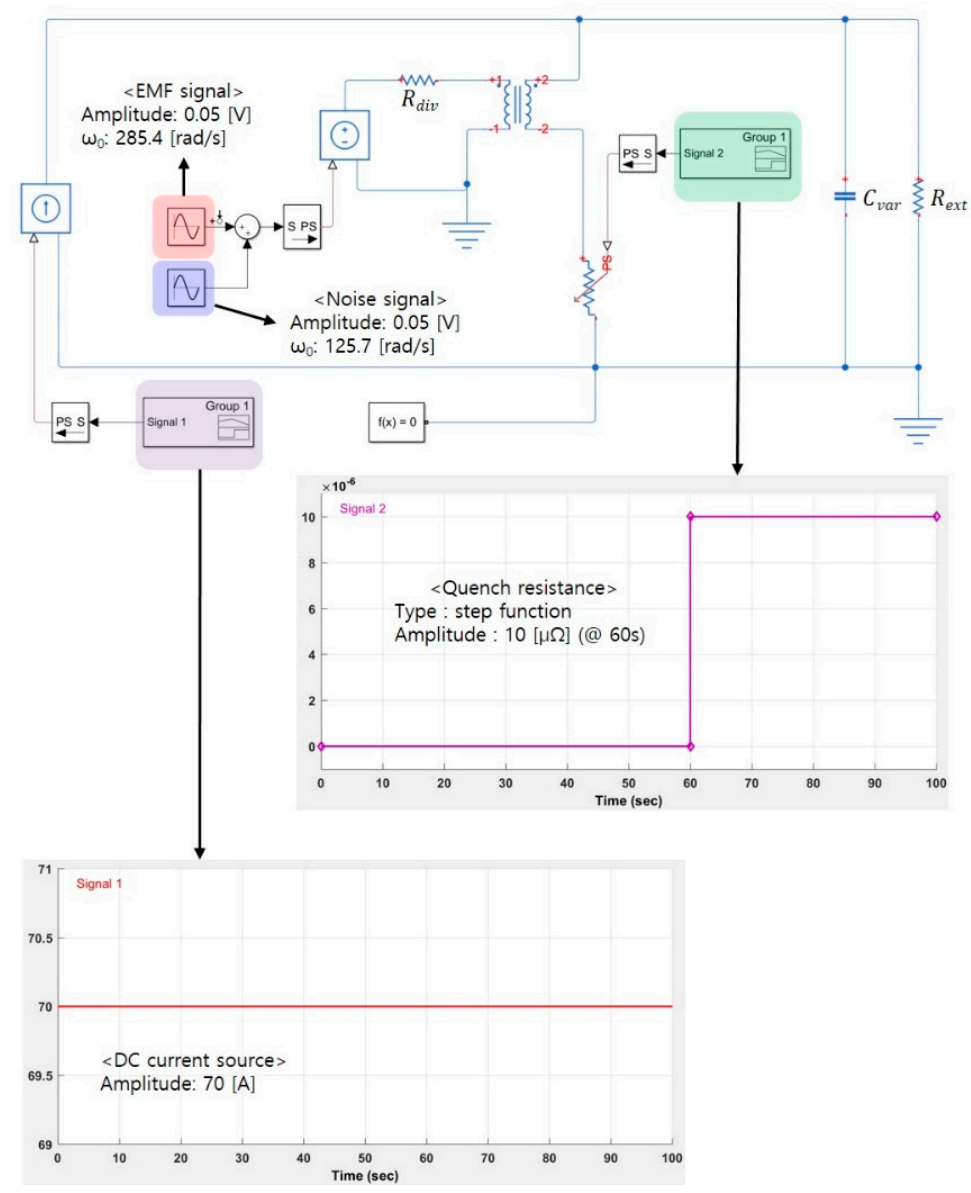

Figure 4. Equivalent circuit of the simulation for verification of the proposed quench detection method.

Electromagnetic force (EMF) and noise signals were applied to the input source of the rotor coil where the EMF signal is the alternating field component generated by the interaction between the rotor and stator coil. The resonance frequency of the circuit was tuned to the EMF signal frequency. A noise signal is an unpredictable noise component in an industrial environment or measurement system. The quench was assumed to occur after $60 \mathrm{~s}$ based on the voltage signal measured at $R_{\text {ext }}$. The quench was generated by heating of the nichrome wire of the heater trigger. The stator coils tested in the simulation were insulated (INS) and not-insulated (NI) coils, respectively.

Table 1 shows the specifications of the simulation parameters and Figure 5 shows results of the FFT analysis of the voltage signal measured at $R_{\text {ext }}$ using the INS coil. As shown in Figure 5, although the amplitude of the EMF and the noise signal are the same value at the input source, the amplitude of these signals measured in $R_{\text {ext }}$ are not the same after performing the FFT analysis. This is because the resonant frequency of the circuit is tuned to the frequency of the EMF signal, so the maximum value of the transfer function curve appears at the resonant frequency of the circuit (Figure 6). 
Table 1. Specifications of the simulation parameters and values.

\begin{tabular}{|c|c|c|c|}
\hline \multicolumn{3}{|c|}{ Parameters } & \multirow{2}{*}{$\begin{array}{c}\text { Values } \\
0.5 \\
45.42\end{array}$} \\
\hline \multirow{2}{*}{$\mathrm{V}_{\mathrm{AC}}$} & EMF & $\begin{array}{c}\text { Peak }\left[\mathrm{V}_{\text {peak }}\right] \\
\text { Frequency }[\mathrm{Hz}]\end{array}$ & \\
\hline & Noise & $\begin{array}{c}\text { Peak }\left[\mathrm{V}_{\text {peak }}\right] \\
\text { Frequency }[\mathrm{Hz}]\end{array}$ & $\begin{array}{l}0.5 \\
20\end{array}$ \\
\hline \multicolumn{3}{|c|}{$\mathrm{R}_{\text {div }}[\mathrm{k} \Omega]$} & 1 \\
\hline \multicolumn{3}{|c|}{$\mathrm{R}_{\mathrm{R}}[\mathrm{m} \Omega]$} & 0.4 \\
\hline \multicolumn{3}{|c|}{$R_{\text {ext }}[\Omega]$} & 5 \\
\hline \multicolumn{3}{|c|}{$\mathrm{I}_{\mathrm{dc}}[\mathrm{A}]$} & 70 \\
\hline \multicolumn{3}{|c|}{$\mathrm{R}_{\theta}[\mu \Omega]$} & 10 \\
\hline \multicolumn{3}{|c|}{$\mathrm{L}_{\mathrm{B}}[\mathrm{mH}]$} & 11.4 \\
\hline \multicolumn{3}{|c|}{$\mathrm{L}_{\mathrm{INS}}[\mathrm{mH}]$} & 0.123 \\
\hline \multicolumn{3}{|c|}{$\mathrm{L}_{\mathrm{NI}}[\mathrm{mH}]$} & 0.125 \\
\hline \multicolumn{3}{|c|}{ Mutual inductance } & 0.04 \\
\hline
\end{tabular}

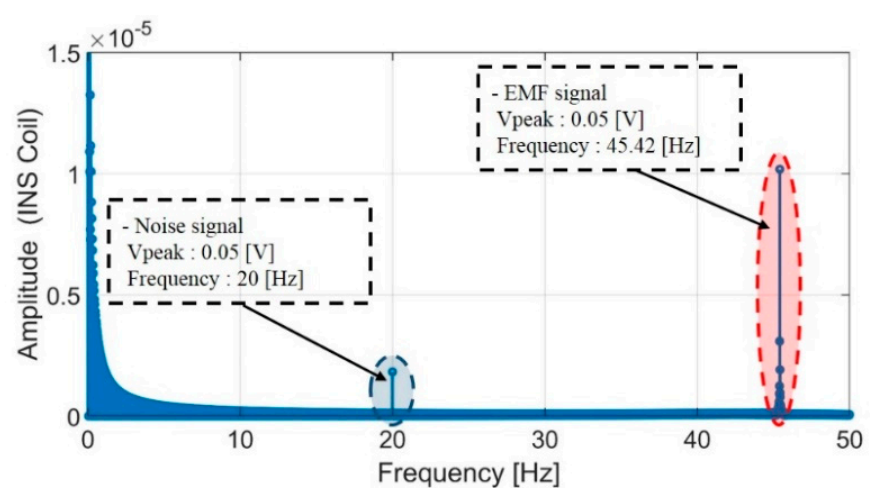

Figure 5. FFT analysis results using the insulated (INS) coil.

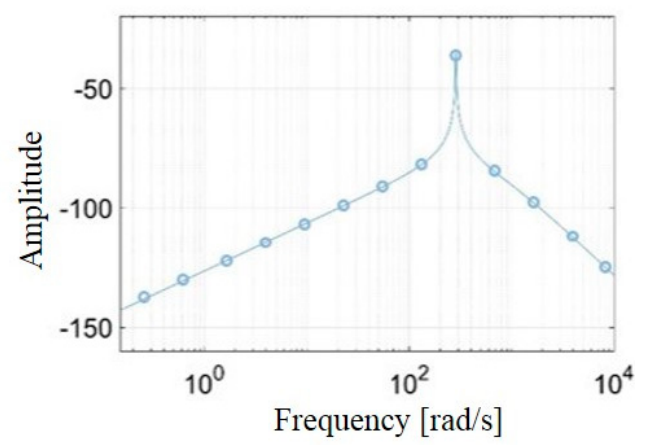

Figure 6. Transfer function shape of the resonant circuit using the INS coil.

Therefore, the amplitude of all other components decreases, except the signal corresponding to the resonance frequency $[16,17]$. However, unlike the result for the INS coil, the noise signal is not filtered using the NI coil, as shown in Figure 7. Therefore, as can be seen in Figure 8, to confirm the reason why the noise signal was not filtered, an equivalent circuit analysis was performed. Figure 9 shows the equivalent circuit using the INS and NI coil. As shown in Figure 9, when the stator coil is NI, there is $R_{R}$, which is the contact resistance between turns of the coil. Moreover, the amplitude of $R_{R}$ is several $\mathrm{m} \Omega$, so that the combined resistance is decreased compared with that of the INS coil. The band-width of the transfer function is inversely proportional to the amplitude of the resistance, therefore, the noise signal was not filtered when the NI coil was used as the stator coil. 


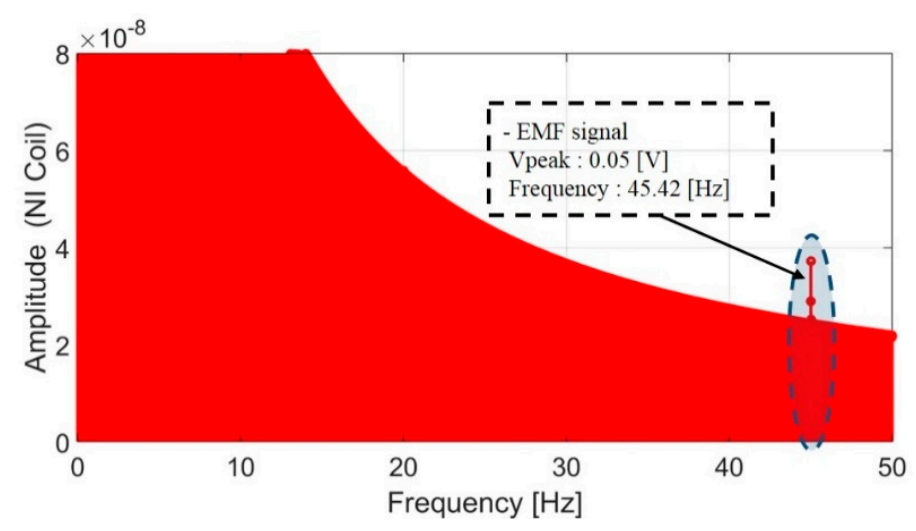

Figure 7. FFT analysis results using the not-insulated (NI) coil.

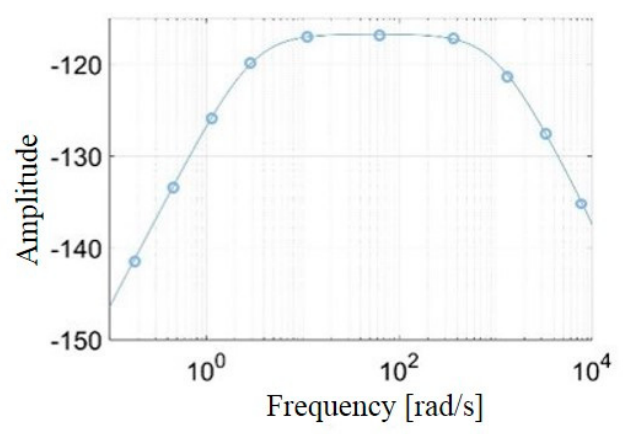

Figure 8. Transfer function shape of the resonant circuit using the NI coil.

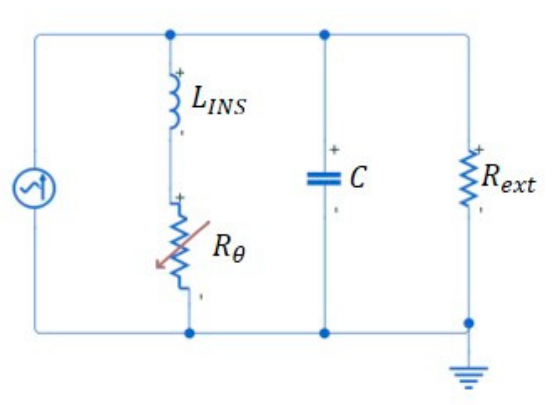

(a)

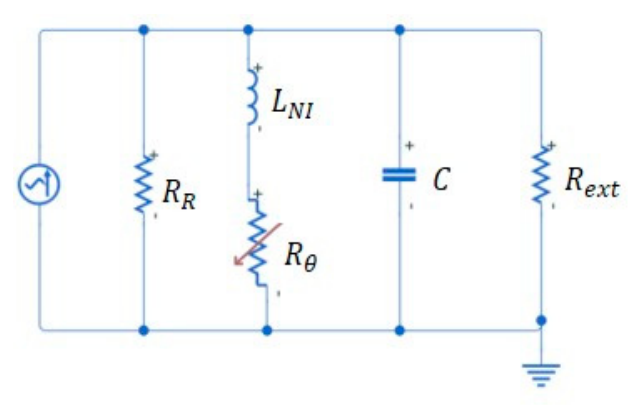

(b)

Figure 9. Equivalent circuit to explain the filter characteristics according to the shape of the transfer function: (a) INS coil and (b) NI coil.

\section{Experimental Results}

An experiment was performed to verify the simulation results of the proposed quench detection method. The experimental set-up used for the verification is shown in Figure 10.

As in the simulation, the amplitudes of the EMF and noise signals are the same values in the experiment. This is because the resonance filter results in a reduction in the amplitude of the noise component, as is the case with the simulation results. In addition, a heater trigger using nichrome wire was installed on the outmost turns of INS and NI coil to cause quenching. The heater trigger was turned on after $60 \mathrm{~s}$ from the start of the voltage measurement. Table 2 shows the specifications of the superconducting coil parameters and values. 


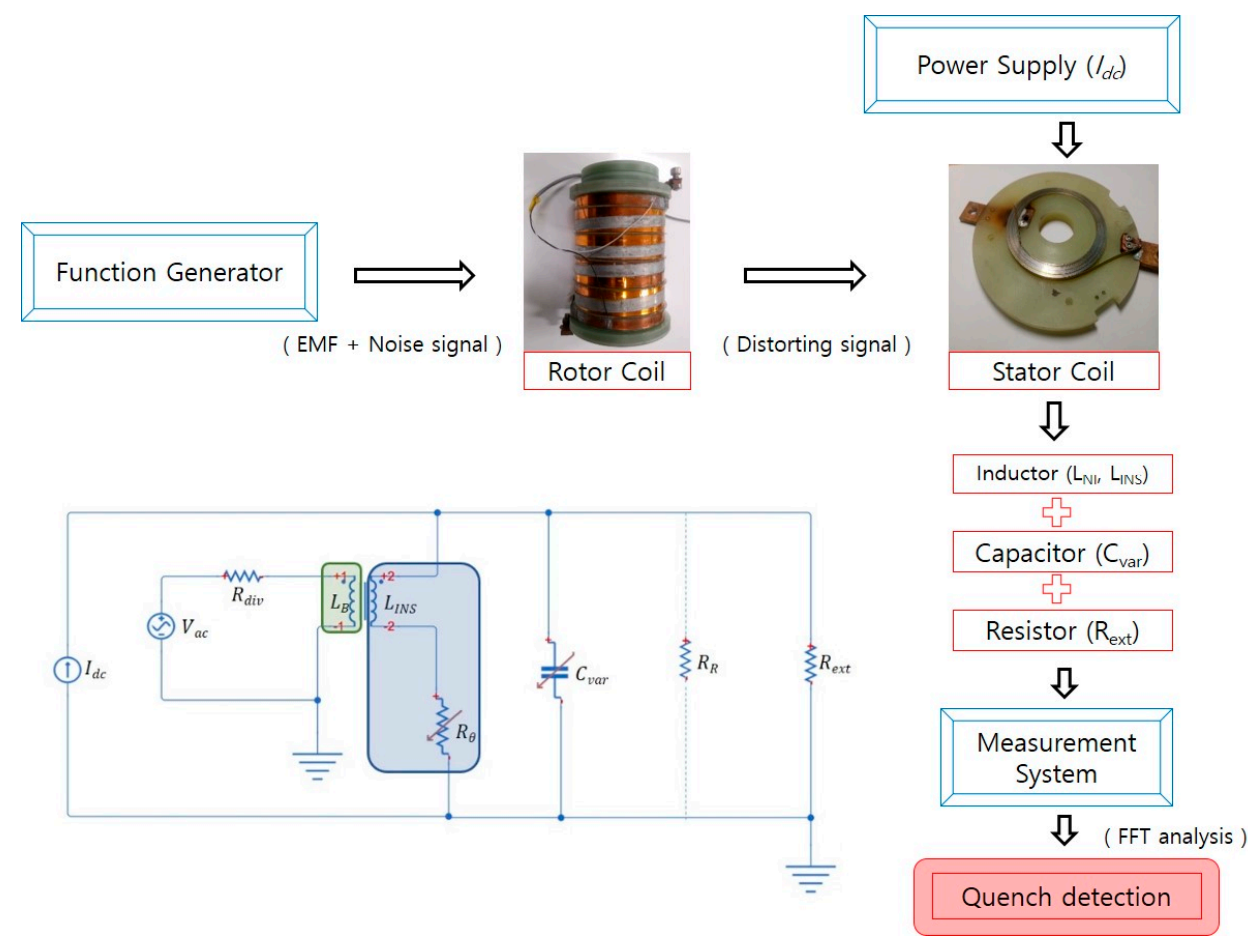

Figure 10. Experimental set-up for verification of the simulation results.

Table 2. Specifications of superconducting coil parameters and values.

\begin{tabular}{|c|c|c|c|}
\hline & \multicolumn{2}{|c|}{ Stator Coil } & \multirow{2}{*}{ Rotor Coil } \\
\hline & NI Coil & INS Coil & \\
\hline IC (@77K, Self) [A] & $<80$ & $<65$ & - \\
\hline Coil Type & \multicolumn{2}{|c|}{ Single Pancake } & Solenoid \\
\hline Turns & \multicolumn{2}{|c|}{30} & - \\
\hline I.D. $[\mathrm{mm}]$ & \multicolumn{2}{|c|}{65} & 100 \\
\hline O.D. [mm] & 80 & 83 & 120 \\
\hline Inductance $[\mathrm{mH}]$ & 0.125 & 0.123 & 11.4 \\
\hline Time Constant $[\mathrm{ms}]$ & 70 & 400 & - \\
\hline Insulation Material/Thickness [mm] & - & \multicolumn{2}{|c|}{ Kapton/0.05 } \\
\hline \multirow{3}{*}{$\begin{array}{c}\text { Width [mm] } \\
\text { Thickness [mm] }\end{array}$} & \multicolumn{3}{|c|}{ SuNAM 2G HTS Tape } \\
\hline & \multicolumn{2}{|c|}{4} & 12 \\
\hline & \multicolumn{3}{|c|}{0.25} \\
\hline
\end{tabular}

Figure 11 shows the experimental results. As shown in Figure 11a, the voltage signal measured at both ends of the $R_{\text {ext }}$ in the time domain. Moreover, in Figure $11 \mathrm{~b}$ and c, are shown the results of the FFT analysis of the experimental results for $0.5 \mathrm{~s}$ in the superconducting and normal state, respectively. However, as can be seen in Figure 11a, although quenching was generated after $60 \mathrm{~s}$, it was difficult to detect the quench in the time domain. The reason for this is that the HTS does not show a significant increase in resistance compared to an LTS, even though a quench occurs. However, comparing the amplitudes of the EMF signals in Figure $11 \mathrm{~b}$ and $\mathrm{c}$ it is possible to confirm that the quench occurs. Moreover, as confirmed from the simulation results, the amplitude of the noise signal decreased due to the effect of the resonant filter. However, in an industrial environment, noise having various frequencies can be included in the measured signal. These noise components should be reduced in the conventional quench detection method. However, because the method proposed in this paper uses only the amplitude change of the EMF signal corresponding to the resonance frequency, these noise 
components are not considered. This is because the amplitude of the noise components is smaller than that of the EMF signal due to the characteristics of the transfer function of the resonance filter. Therefore, only the frequency component corresponding to the EMF signal is measured to detect the quench. Figure 12 shows the results of FFT analysis using a $70 \mathrm{~Hz}$ signal corresponding to the resonance frequency of the circuit. As shown in Figure 12, it is possible to distinguish between the superconducting state and the normal state based on the $60 \mathrm{~s}$ when the heater trigger is turned on, so that the quench can be detected. Another advantage of the proposed quench detection method is that the quench detection time can be reduced by changing the window size $(\mathrm{N})$ corresponding to an integer multiple of the EMF frequency at which the FFT analysis is performed. That is, by increasing the number of FFT analyses that can be performed at the same time, it is possible to increase the probability of detecting a quench signal.

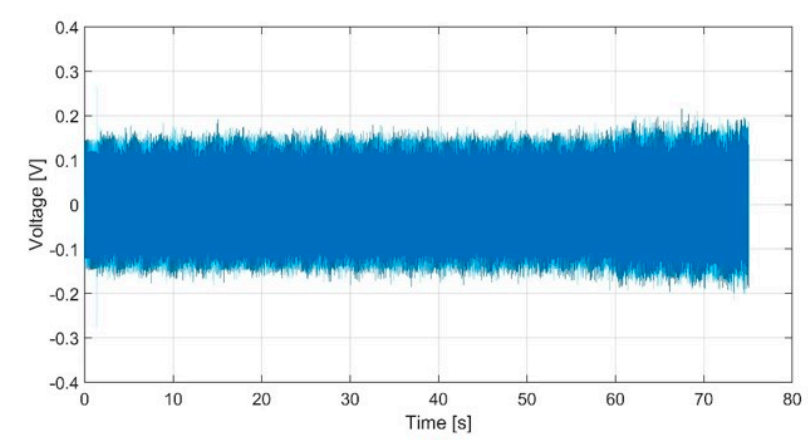

(a)
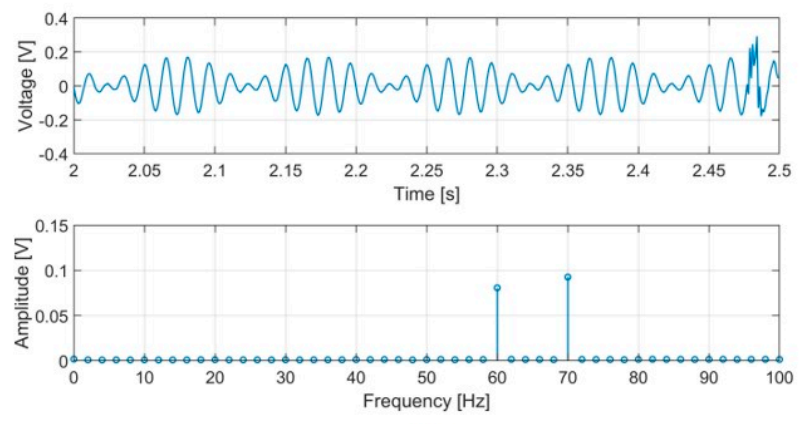

(b)
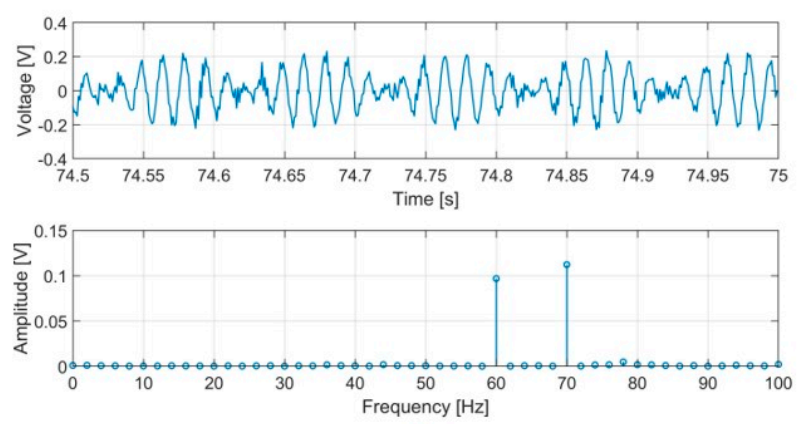

(c)

Figure 11. Experimental results: (a) voltage signal measured at $R_{\text {ext }}$, (b) FFT analysis in the superconducting state, and (c) FFT analysis in the normal state. 


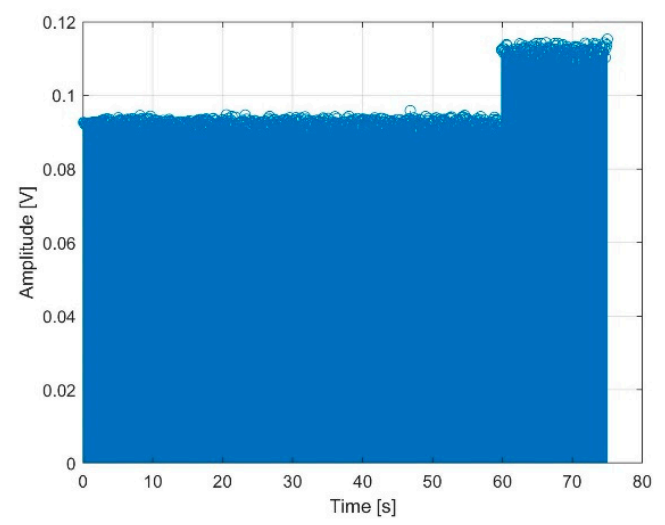

(a)

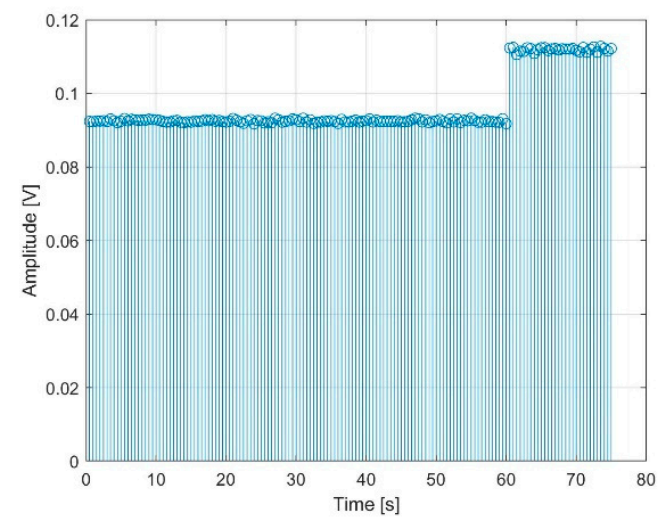

(b)

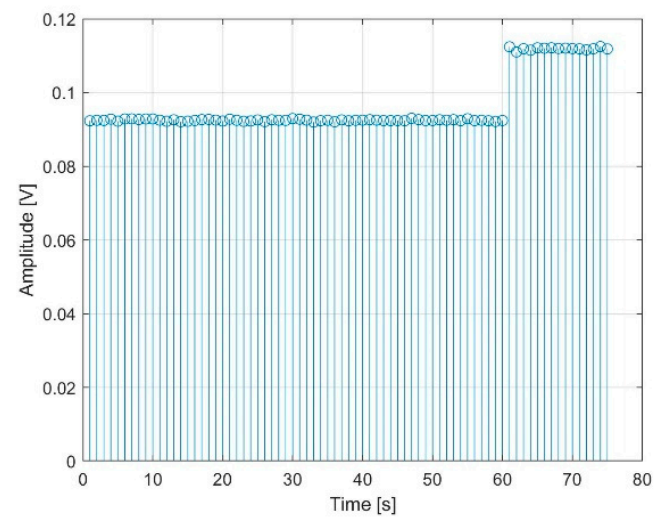

(c)

Figure 12. FFT analysis results of the electromagnetic force (EMF) signal $(@ 70 \mathrm{~Hz}):(\mathbf{a}) \mathrm{N}=100,(\mathbf{b}) \mathrm{N}=$ 500 , and (c) $\mathrm{N}=1000$.

\section{Discussion and Outlooks}

The quench voltage of the INS coil used in the experiment is $1.3 \mathrm{mV}$ based on $1 \mu \mathrm{V} / \mathrm{cm}$ because the total length of the superconducting tape wound on the INS coil was $13 \mathrm{~m}$ as shown in Table 2 [18-20]. In Figure 12a, when the INS coil is in the superconducting state, the standard deviation is $0.8 \mathrm{mV}$, which is $0.5 \mathrm{mV}$ less than the quench voltage. Also, in Figure 12a, the number of points is 600 and 153 in the superconducting and normal state, respectively. Table 3 shows the confusion matrix based on the results in Figure 12a.

Table 3. Confusion matrix of quench detection.

\begin{tabular}{lcc}
\hline & Condition Positive & Condition Negative \\
\hline Predicted Condition Positive & $\begin{array}{c}\text { True Positive }(=153) \\
\text { True Positive Rate }(=1)\end{array}$ & $\begin{array}{c}\text { False Positive }(=27) \\
\text { False Positive Rate }(=0.045)\end{array}$ \\
\hline Predicted Condition Negative & $\begin{array}{c}\text { False Negative }(=0) \\
\text { False Negative Rate }(=0)\end{array}$ & $\begin{array}{c}\text { True negative }(=573) \\
\text { True negative Rate }(=0.955)\end{array}$ \\
\hline
\end{tabular}

As shown in Table 3, false positive rate is a ratio that is mistakenly determined as quench when the INS coil is in a superconducting state. Also, true positive rate means the ratio of determination as quench when the INS coil is in a normal state. Therefore, this results mean that the percentage of false alarm is $4.5 \%$ when the INS coil is in the superconducting state, and the percentage of detecting quench when it is in the normal state is $100 \%$. However, when the quench voltage is set to three times, 
the percentage of false alarm converges to $0 \%$ [21]. Also the sampling rate for data acquisition was 1 $\mathrm{kHz}$, so resolution was 10 when the window size is 100 . Here, the window size is a minimum value in which the spectral leakage does not occur. In this case, the quench detection can be performed every $0.1 \mathrm{~s}[22,23]$. However, the quench detection time can be performed faster depending on the resonance frequency, sampling rate and window size. Therefore, the effect of applying the proposed system to the INS coil has been confirmed. However, it is necessary to examine further the applicability of this method to the metal clad superconducting coil and the LTS coil $[24,25]$.

It was confirmed through experiments that the quench detection method proposed in this paper can increase the reliability of quench detection compared to a system that detects abnormal signals in time domain using a conventional voltage tap. We also confirmed the advantage of reducing detection time, which is one of the most important factors to consider in designing the quench detection system. However, in order to apply this method, a capacitor having a capacity that can be tuned to the resonance frequency of the system is required. In addition, when this method is applied to a system other than HTS rotating machinery, an additional AC source is required to satisfy the resonance condition.

\section{Conclusions}

In this paper, we proposed a new quench detection method for HTS rotating machinery. In the HTS rotating machinery, unpredictable noise components are generated by the interaction between the HTS rotor coil and industrial environment. For sensitive quench detection, these noise components act as inhibitors, therefore, an RLC resonance filter was used to reduce the influence of the noise components. That is, the amplitude of the noise signal (except for the EMF signal) can be reduced as shown in Figure 5, using an INS coil. However, the quench detection method proposed in this paper is difficult to apply to the NI coil because of the wide band-width of the transfer function shape as shown in Figures 7 and 8, respectively. Moreover, in order to overcome the drawback of quench detection due to the slow NZPV of an HTS, FFT analysis was performed. As shown in Figures 11 and 12, we confirmed that quenching can be detected in the frequency domain through FFT analysis by comparing the amplitude of the transfer function. Moreover, the quench detection time can be shortened by adjusting the window size of the moving average filter. As a result, it is expected that the new method can be applied to HTS rotating machinery for sensitive quench detection.

Author Contributions: Conceptualization, S.S.; methodology, S.S., S.L., and Y.C.; software, S.S. and Y.C.; validation, S.S., T.K.K., and S.L.; formal analysis, S.S.; investigation, S.S. and S.L.; resources, T.K.K.; data curation, S.S.; writing - original draft preparation, S.S.; funding acquisition, T.K.K. and S.L. All authors have read and agreed to the published version of the manuscript.

Funding: This work was supported by the Korea Basic Science Institute under Grant D39611.

Conflicts of Interest: The authors declare no conflict of interest.

\section{References}

1. Ravaioli, E.; Davis, D.; Marchevsky, M.; Sabbi, G.; Shen, T.; Verweij, A.; Zhang, K. A new quench detection method for HTS magnets: Stray-capacitance change monitoring. Phys. Scr. 2019, 95, 015002. [CrossRef]

2. Marchevsky, M.; Gourlay, S.A. Acoustic thermometry for detecting quenches in superconducting coils and conductor stacks. Appl. Phys. Lett. 2017, 110, 012601. [CrossRef]

3. Makoto, T. An Acoustic Quench Detection Method for CICC Conductor Operating in Gas or Liquid. IEEE Trans. Appl. Supercond. 2019, 29, 4702305.

4. Ryan, D.T.; Laskaris, E.T.; Huang, X. Quench Monitoring and Control System and Method of Operating Same. U.S. Patent 7,053,509,B2, 30 May 2006.

5. Wang, X.; Guan, M.; Ma, L. Strain-based quench detection for a solenoid superconducting magnet. Supercond. Sci. Technol. 2012, 25, 095009. [CrossRef]

6. Hu, Q.; Wang, X.; Guan, M.; Wu, B. Strain responses of superconducting magnets based on embedded polymer-FBG and cryogenic resistance strain gauge measurements. IEEE Trans. Appl. Supercond. 2018, 29, 8400207. [CrossRef] 
7. Nanato, N.; Yanagishita, M.; Nakamura, K. Quench detection of Bi-2223 HTS coil by partial active power detecting method. IEEE Trans. Appl. Supercond. 2001, 11, 2391-2393. [CrossRef]

8. Wei, B.; Yang, Y.; Qiu, M.; Zhang, H.; Zhu, J.; Chen, P.; Zhu, D.; Lai, X. The quench detection system for YBCO superconducting magnets. IEEE Trans. Appl. Supercond. 2010, 20, 1369-1372.

9. Nanato, N.; Nakamura, K. Quench detection method without a central voltage tap by calculating active power. Cryogenics 2004, 44,1-5. [CrossRef]

10. Hasegawa, S.; Ito, S.; Nishijima, G.; Hashizume, H. Fundamental Evaluations of Applicability of LTS Quench Detectors to REBCO Pancake Coil. IEEE Trans. Appl. Supercond. 2019, 29, 9001305. [CrossRef]

11. Collier, K.A.; Sengupta, S.; Espinosa, C.A.; Kelly, J.E.; Kelz, J.I.; Martin, R.W. Design and construction of a quadruple-resonance MAS NMR probe for investigation of extensively deuterated biomolecules. J. Magn. Reson. 2017, 285, 8-17. [CrossRef]

12. Gan, Z.; Hung, I.; Wang, X.; Paulino, J.; Wu, G.; Litvak, I.M.; Gor'kov, P.L.; Brey, W.W.; Lendi, P.; Schiano, J.L.; et al. NMR spectroscopy up to $35.2 \mathrm{~T}$ using a series-connected hybrid magnet. J. Magn. Reson. 2017, 284, 125-136. [CrossRef] [PubMed]

13. Hwang, Y.J.; Ahn, M.C.; Lee, T.S.; Lee, W.S.; Ko, T.K. Experimental study of the effect of alternating fields on HTS coils According to the winding insulation conditions. Supercond. Sci. Technol. 2013, 26, 085021. [CrossRef]

14. Song, S.; Choi, Y.; Lee, W.S.; Sim, K.; Hwang, Y.J.; Jang, J.Y. Analytic Study of the Active Quench Detection Method for High-Temperature Superconducting Magnet Using Resonance Circuit. IEEE Trans. Appl. Supercond. 2018, 28, 4701304. [CrossRef]

15. Hahn, S.; Kim, Y.; Voccio, J.L.; Park, D.K.; Bascuñán, J.; Lee, H.S. Yukikazu Iwasa No-Insulation Coil Under Time-Varying Condition: Magnetic Coupling with External Coil. IEEE Trans. Appl. Supercond. 2013, 23, 4601705. [CrossRef]

16. Prommee, P.; Thongdit, P.; Angkeaw, K. Log-domain high-order low-pass and band-pass filters. Int. J. Electron. Commun. 2017, 79, 234-242. [CrossRef]

17. Huang, Q.; Rajashekara, K. Virtual RLC active damping for grid-connected inverters with LCL filters. IEEE Appl. Power Electron. Conf. Expo. (APEC) 2017, 424-429. [CrossRef]

18. Murta-Pina, J.; Vilhena, N.; Arsénio, P.; Pronto, A.; Álvarez, A. Preliminary Design and Test of Low-Resistance High Temperature Superconducting Short-Circuited Coils. IEEE Trans. Appl. Supercond. 2018, 28, 4604105. [CrossRef]

19. Xie, Y.; Quyang, Z.; Shi, L.; Kuang, Z.; Meng, M. Experimental studies of diffusion welding of YBCO to copper using solder layers. IOP Conf. Ser. Mater. Sci. Eng. 2017, 171, 012155. [CrossRef]

20. Choi, Y.; Lee, W.S.; Song, S.; Jeon, H.; Ko, T.K. A New Quench Protection System Using Dual-Capacitor Switching for Fast Energy Extraction from HTS Magnets. IEEE Trans. Appl. Supercond. 2019, 29, 4702905. [CrossRef]

21. Lee, J.; Ko, T.K. Estimation of the Engineering Critical Current Criteria for HTS Wire Carrying an Alternating Current. IEEE Trans. Appl. Supercond. 2014, 24, 9001705.

22. Claeys, T.; Vanoost, D.; Peuteman, J.; Vandenbosch, G.A.E.; Pissoort, D. An iterative interpolated dft to remove spectral leakage in time-domain near-field scanning. IEEE Trans. Electromagn. Compat. 2017, 60, 202-210. [CrossRef]

23. Hasegawa, S.; Ito, S.; Hashizume, H. Numerical and Experimental Evaluations of the Quench Detection Performance of an $\mathrm{YBCO} / \mathrm{Nb}-\mathrm{Ti}$ d Tape. IEEE Trans. Appl. Supercond. 2018, 28, 4700605. [CrossRef]

24. Ahn, M.C.; Yang, H.; Kim, K.; Jang, J.Y.; Lee, S.; Hahn, S. Optimal design methodology of multiwidth HTS magnet for minimum wire consumption. IEEE Trans. Appl. Supercond. 2018, 28, 4602905. [CrossRef]

25. Jang, J.; Yoon, S.; Hahn, S.; Hwang, Y.J.; Kim, J.; Shin, K.H.; Cheon, K.; Kim, K.; In, S.; Hong, Y.; et al. Design, construction and $13 \mathrm{~K}$ conduction-cooled operation of a $3 \mathrm{~T} 100 \mathrm{~mm}$ stainless steel cladding all-REBCO magnet. Supercond. Sci. Technol. 2017, 30, 105012. [CrossRef]

(C) 2019 by the authors. Licensee MDPI, Basel, Switzerland. This article is an open access article distributed under the terms and conditions of the Creative Commons Attribution (CC BY) license (http://creativecommons.org/licenses/by/4.0/). 